\title{
PENGARUH KONSELING LAKTASI PADA IBU HAMIL TRIMESTER III TERHADAP PEMBERIAN PRELAKTAL BAYI BARU LAHIR
}

\author{
Happy Dwi Aprilina ${ }^{1}$, Risanto Siswosudarmo ${ }^{2}$, Wahyu Ikka Setiyarini ${ }^{3}$
}

\begin{abstract}
Background: Exclusive breastfeeding's rate in Indonesia is still low. One of the causes of this failure is the prelacteal feeding in infants' early life. Prelacteal feeding can cause the infants reluctance to suckle their mothers' breasts, diarrhea, allergy, ear infections and respiratory disorders in infants. One of the efforts to prevent prelacteal feeding is providing lactation counselingto women in the third trimester of pregnancy. Objective: To assess the impact of lactation counseling to women in the third trimester of pregnancy toward prelacteal feeding to newborn infants.

Method: This research design usedrandomized controlled trial (RCT) which is divided into treatment group (pregnant women class and individual lactation counseling) $n=33$ and control group (pregnant women class only) $n=34$. The subjects are woman in the third trimester of pregnancy in the work area of Puskesmas Sokaraja 1, Banyumas. The sampling technique is simple random sampling. Chi square, relative risk (RR) and logistic regression analysis is used for statistical analysis.

Result and Discussion: Proportion mothers who did not give prelacteal feeding wassignificantly higher in intervention group than in control group, $69 \%$ vs $30 \%$ with RR $=1.69(95 \% \mathrm{Cl}: 1.06$ to 2.68$) \mathrm{p}=0.01$.

Conclusion: Mothers who received counseling lactation in the third trimester of pregnancy had a 1.69 times greater chance to not give prelacteal than mothers who did not receive counseling lactation.
\end{abstract}

Keywords: Exclusive Breastfeeding, Lactation Counseling, Prelacteal, Health Education, Breastfeed

\begin{abstract}
ABSTRAK
Latar Belakang: Cakupan pemberian ASI Eksklusif di Indonesia masih dalam rendah. Salah satu penyebab kegagalan ASI Eksklusif adalah pemberian prelaktal pada awal kehidupan bayi. Pemberian prelaktal dapat menyebabkan bayi malas menyusu, diare, alergi, infeksi dan gangguan pernapasan pada bayi. Salah satu upaya dalam mencegah pemberian prelaktal yaitu dengan memberikan konseling laktasi pada ibu hamil trimester ketiga.
\end{abstract}

Tujuan: mengetahui pengaruh konseling laktasi pada ibu hamil trimester ketiga terhadap pemberian prelaktal bayi baru lahir.

Metode: Desain penelitian menggunakan randomized controlled trial (RCT),dibagi menjadi kelompok perlakuan (kelas ibu hamildan konseling laktasi) $n=33$ dan kelompok kontrol (kelas ibu hamil saja) $n=34$. Subjek penelitian yaitu ibu hamil trimester ketiga di wilayah kerja Puskesmas Sokaraja 1 Banyumas. Teknik pengambilan sampel menggunakan simple random sampling. Chisquare, risiko relatif (RR) dan analisis regresi logistik digunakan untuk analisis statistik.

Hasil dan Pembahasan: Proporsi ibu tidak memberikan prelaktal pada kelompok intervensi lebih tinggi dibandingkan dengan kelompok kontrol; $69 \%$ vs 30\% dengan $\mathrm{RR}=1,69$ (95\% $\mathrm{Cl}: 1,06-2,68)$, sehingga

\footnotetext{
E-mail: happydwiaprilina@yahoo.com; Program Studi Magister Keperawatan Universitas Gadjah Mada

Bagian Obstetri dan Ginekologi Fakultas Kedokteran Universitas Gadjah Mada

Rumah Sakit Umum Daerah Banyumas
} 
terdapat perbedaan yang bermakna secara statistik pada kelompok perlakuan dibandingkan dengan kelompok kontrol

Kesimpulan: Proporsi ibu yang mendapatkan konseling laktasi pada kehamilan trimester ketiga 1,69 kali berpeluang lebih besar tidak memberikan prelaktal daripada ibu yang tidak mendapatkan konseling laktasi.

Kata kunci: ASI Eksklusif, Konseling laktasi, Prelaktal, Pendidikan Kesehatan, Menyusui

\section{PENDAHULUAN}

Millenium Development Goals (MDG's) merupakan deklarasi milenium hasil kesepakatan dari 189 negara Perserikatan Bangsa-Bangsa (PBB) yang mulai dijalankan pada bulan September 2010. Secara umum, target MDG's yaitu agar tercapainya kesejahteraan rakyat dan pembangunan masyarakat pada tahun 2015. MDG's menjalankan delapan butir tujuan yang harus dicapai pada tahun 2015. Diantara delapan target tersebut, target keempat adalah menurunkan angka kematian anak. Salah satu indikatornya yaitu angka kematian bayi menurun sebesar 23/1000 kelahiran hidup. ${ }^{1}$

Berdasarkan angka kematian bayi di Jawa Tengah tahun 2012 sebesar 10,75/1.000 kelahiran hidup, hal tersebut meningkat jika dibandingkan dengan tahun 2011 yaitu sebesar 10,34/1.000 kelahiran hidup. ${ }^{2}$ Sesuai dengan pendapat diatas, angka kematian bayi di Kabupaten Banyumas mengalami peningkatan tiap tahunnya. Pada tahun 2010 sebesar 7,1/1.000 kelahiran hidup, pada tahun 2011 meningkat menjadi 10,31/1.000 kelahiran hidup dan tahun 2012 sebesar 10.60/1.000 kelahiran hidup. $^{3}$ Salah satu puskesmas di Kabupaten Banyumas yaitu wilayah kerja Puskesmas Sokaraja 1 didapatkan angka kematian bayi tiap tahunnya mengalami peningkatan. Pernyataan tersebut terbukti dengan data angka kematian bayi yang meningkat pada tahun 2012 sebesar 13,5/1.000 kelahiran hidup dan pada tahun 2013 meningkat menjadi 14,3/1.000 kelahiran hidup.
Berdasarkan data di atas khususnya di wilayah kerja Puskesmas Sokaraja I angka kematian bayi sudah memenuhi target MDGs. Namun, tiap tahunnya masih terjadi peningkatan angka kematian bayi. Untuk itu perlu adanya usaha untuk tetap menurunkan angka kematian bayi di wilayah tersebut.

Salah satu program untuk menurunkan angka kematian bayi yaitu merekomendasikan agar bayi mendapatkan ASI Eksklusif selama 6 bulan. Setelah 6 bulan, bayi baru dapat diberikan makanan pendamping ASI (MP-ASI) dan ibu tetap memberikan ASI sampai minimal anak berusia 2 tahun. ${ }^{4}$ ASI eksklusif adalah menyusui selama 6 bulan tanpa memberikan makanan atau minuman lain termasuk air putih, susu formula maupun makanan lainnya, kecuali obat-obatan, vitamin ataupun mineral tetes. ${ }^{5}$

Menurut Riskesdas ${ }^{6}$, cakupan pemberian ASI Eksklusif di Indonesia pada bayi usia 6 bulan sebesar 30,2\%. Berbeda dengan Dinas Kesehatan Banyumas, Sedangkan cakupan pemberian ASI Eksklusif di Kabupaten Banyumas pada bayi 0-6 bulan sebesar 53.6\%, dan di wilayah kerja Kecamatan Sokaraja lebih besar yaitu $53.9 \%^{3}$. Menurut Rachmad ${ }^{7}$, persentase tersebut dikategorikan rendah karena pada tahun 2015 target pemberian ASI Eksklusif di Indonesia meningkat sebesar $80 \%$.

Pemberian ASI Eksklusif sering mengalami kegagalan, hal ini disebabkan oleh beberapa faktor. Faktor yang mempengaruhi kegagalan pemberian ASI selama dua bulan yaitu ibu 
pekerja sebesar $52,6 \%$, persalinan tidak normal sebesar 32,9\%, pendidikan rendah sebesar $28.3 \%$, pengenalan awal bukan ASI (prelaktal) sebesar 42.1\%, mindset/pikiran ibu untuk memberikan bayinya ASI dan susu formula atau makanan pendamping ASI sebesar 52\%, paritas $\geq 3$ sebesar $32.2 \%$, keadaan ibu sakit sebesar $32.9 \%$ dan frekuensi ANC kurang lengkap sebesar $10.5 \% .^{8}$ Menurut Sholichah ${ }^{9}$, penyebab dominan kegagalan menyusui eksklusif adalah ibu menganggap bayi yang menangis disebabkan lapar, jadi perlu diberikan makanan tambahan/ prelaktal.

Prelaktal diberikan kepada bayi baru lahir dengan alasan ASI belum keluar atau ASI keluar sedikit sehingga bayi kelaparan. Alasan lainnya adalah adanya kepercayaan/kebiasaan untuk memberikan makanan/minuman selain ASI sebelum ASI keluar. Pemberian prelaktal pada bayi akan mengakibatkan bayi malas menyusu ibunya karena bayi sudah puas dan merasa kenyang. Hal tersebut yang menyebabkan produksi ASI terhambat dan tidak lancar. Bayi yang diberikan prelaktal akan lebih banyak terserang gangguan pencernaan, konstipasi, diare, alergi, infeksi telinga dan gangguan pernapasan, karena bayi belum siap mencerna makanan atau minuman kecuali ASI. Masalah bayi baru lahir tersebut dapat menyebabkan Sudden Infant Death (SID) atau kematian mendadak pada bayi. ${ }^{10}$

Pemberian prelaktal pada bayi baru lahir di Indonesia masih dalam kategori tinggi yaitu sebesar $43,6 \%$, sedangkan data di Jawa Tengah sebesar 43,2\%. ${ }^{6}$ Hal tersebut didukung oleh Rosha and Utami ${ }^{11}$ yang menyatakan bahwa 44\% bayi diberikan makanan prelaktal di Kelurahan Kebon Kelapa dan Ciwaringin, Kota Bogor Tengah.

Penelitian Nguyen, Keithly ${ }^{12}$ menyatakan bahwa ada beberapa faktor penyebab pemberian prelaktal. Faktor pertama, adanya persepsi ibu yang salah tentang pemberian ASI
$52,4 \%$, Faktor kedua, promosi susu formula di fasilitas kesehatan sebesar 46,3\%. Faktor ketiga, kurangnya dukungan keluarga saat hamil ataupun saat periode kritis dalam tiga hari pertama sebesar $10,6 \%$. Faktor lainnya adalah kurang pengetahuan ibu tentang ASI, cara menyusui kurang tepat, melahirkan dengan operasi cesar dan episiotomi. Penelitian tersebut didukung oleh Nirmalasari ${ }^{13}$, pemberian prelaktal pada bayi baru lahir dengan alasan bayi menangis dan ASI belum keluar sebesar 35,5\%.

Untuk mencegah pemberian prelaktal, Nguyen, Keithly ${ }^{12}$ menyarankan adanya intervensi yang tepat terutama selama berada di pelayanan kesehatan. Salah satu intervensi yang dapat mencegah pemberian prelaktal adalah memberikan dukungan dan konseling pada saat antenatal, perinatal dan manajemen postnatal yang baik. Pemberian konseling dimulai pada saat antenatal terutama pada ibu hamil di trimester ketiga, karena pada trimester ketiga ibu cukup fokus dalam mempersiapkan proses persalinan dan pemberian nutrisi yang baik untuk bayinya. Konseling laktasi dapat meningkatkan pengetahuan, merubah persepsi yang salah serta meningkatkan kepercayaan diri ibu dalam memberikan ASI Eksklusif.

Penelitian tersebut didukung oleh Moore and Coty ${ }^{14}$, yang menyatakan bahwa ibu harus mendapatkan informasi tentang menyusui sebelum melahirkan. Informasi tersebut harus berdasarkan bukti ilmiah, konsisten dan realistis. Pada kelompok prenatal, tema konseling yaitu manfaat menyusui bagi bayi dan ibu, ketersediaan dukungan dari keluarga dan lingkungan sekitar serta mengambil keputusan akan memberikan ASI saja. Pada kelompok postnatal, informasi yang penting untuk diberikan adalah cara menyusui yang benar, pentingnya dukungan suami dan orang sekitar, menerima saran serta memvalidasi pengalaman dan niat dalam proses menyusui eksklusif. 
Berdasarkan hasil survey di wilayah kerja Puskesmas Sokaraja 1, dengan 15 responden ibu pasca melahirkan didapatkan 12 bayi baru lahir (80\%) diberikan prelaktal. Penyuluhan kesehatan tentang ASI Eksklusif sudah dilakukan di wilayah tersebut pada saat prenatal, intranatal dan postnatal. Pada saat prenatal, ada program kelas ibu hamil yang salah satu programnya adalah penyuluhan kesehatan tentang ASI Eksklusif. Inisiasi Menyusui Dini (IMD) dilaksanakan saat ibu setelah melahirkan bayi (intranatal). Pada masa postnatal, ibu diajarkan cara menyusui yang benar. Meskipun penyuluhan kesehatan telah diberikan, beberapa ibu masih memberikan prelaktal.Alasan memberikan prelaktal adalah ASI belum keluar dan bayi nangis karena lapar serta anggapan yang salah tentang kolostrum. Biasanya ibu mulai memberikan prelaktal setelah 4-8 jam setelah melahirkan.

Hal tersebut diduga kurangnya konseling tentang ASI Eksklusif yang disertai tentang bahaya pemberian prelaktal. Maka dari itu, perlu adanya konseling laktasi pada ibu hamil trimester ketiga di wilayah kerja Puskesmas Sokaraja 1 Kabupaten Banyumas, sehingga ibu tidak memberikan prelaktal pada bayi baru lahir.

\section{METODE}

Penelitian ini dirancang menggunakan metode Randomized Controlled Trial (RCT) yang dibagi menjadi 2 kelompok yaitu kelompok perlakuan dan kelompok kontrol dengan single blind.Asisten peneliti tidak tahu subjek yang menjadi kelompok perlakuan atau kelompok kontrol. Kelompok perlakuan $(n=33)$ mendapatkan kelas ibu hamil dan konseling laktasi per individu, sedangkan kelompok kontrol $(n=34)$ hanya mendapatkan kelas ibu hamil saja.
Populasi dalam penelitian ini adalah ibu hamil trimester ketiga di wilayah kerja Puskesmas Sokaraja 1 Kabupaten Banyumas, Jawa Tengah. Sampelpenelitian yang memenuhi kriteria inklusi yaitu usia kehamilan ibu $\geq 32$ minggu yang dihitung dengan HPHT/USG, tafsiran berat janin minimal 1800 gram, berdomisili di wilayah kerja Puskesmas Sokaraja $1 \mathrm{Kab}$. Banyumas, setelah melahirkan (3×24 jam setelah melahirkan), ibu dan bayi akan kembali ke wilayah kerja Puskesmas Sokaraja 1 Kab. Banyumasdan ibu hamil yang berkeinginan menyusui bayinya. Kriteria Eksklusia adalah ibu hamil yang tidak bersedia menjadi responden, ibu tidak ada atau ibu terpisah dari bayi seperti meninggal dunia, ibu dan bayi tidak rawat gabung, indikasi medis perlu diberikan prelaktal dan bayi mengalami kesulitan saat menyusu/mengalami cacat bawaan .

Teknik pengambilan sampel dalam penelitian ini adalah simple random sampling yang diacakdengan program komputer. Data dianalisismenggunakan uji statistik chi square.

\section{HASIL DAN PEMBAHASAN}

\section{Karakteristik Subyek Penelitian}

Responden dalampenelitian iniadalah ibu hamil trimester III di wilayah kerja Puskesmas Sokaraja 1 Kabupaten Banyumas yang berjumlah 72 ibu hamil. Responden tersebut dibagi menjadi 2 kelompok yaitu kelompok perlakuan yang mendapatkan kelas ibu hamil dan konseling laktasi per individu sedangkan kelompok kontrol mendapatkan kelas ibu hamil saja. Karakteristik responden meliputi: usia ibu, tingkat pendidikan, kebiasaan prelaktal, dukungan keluarga, pekerjaan, dukungan petugas kesehatan, paritas dan jenis persalinan. 
Tabel 1. Karakteristik Subjek Penelitian

\begin{tabular}{|c|c|c|c|}
\hline No. & Karakteristik & $\mathrm{N}$ & $\%$ \\
\hline \multirow[t]{3}{*}{1.} & Umur Ibu & & \\
\hline & a. 20-35 tahun & 58 & 86,56 \\
\hline & b. $<20,>35$ & 9 & 13,44 \\
\hline \multirow[t]{3}{*}{2.} & Tingkat Pendidikan & & \\
\hline & a. Pendidikan tinggi & 34 & 50,75 \\
\hline & b. Pendidikan rendah & 33 & 49,25 \\
\hline \multirow[t]{3}{*}{3.} & Pekerjaan & & \\
\hline & a. Bekerja & 8 & 11,94 \\
\hline & b. Tidak bekerja & 59 & 88,06 \\
\hline \multirow[t]{3}{*}{4.} & Paritas & & \\
\hline & a. Primipara & 34 & 50,75 \\
\hline & b. Multipara & 33 & 49,25 \\
\hline \multirow[t]{3}{*}{5.} & Jenis Persalinan & & \\
\hline & a. Normal & 46 & 68,65 \\
\hline & b. Tidak normal & 21 & 31,35 \\
\hline
\end{tabular}

Tabel 1 menunjukkan bahwa karakteristik responden secara mayoritas untuk setiap item adalah ibu berumur 20-35 tahun sebesar 58
(86,56\%), tingkat pendidikan tinggi sebesar 34 $(50,75 \%)$, ibu tidak bekerja sebesar $59(88,06 \%)$, ibuprimipara sebesar $34(50,75 \%)$, ibu yang bersalin normal sebesar $46(68,66 \%)$.

\section{Komparabilitas Pemberian Prelaktal Bayi Baru Lahir}

Tabel 2 terlihat bahwa karakteristik responden yaitu umur ibu, tingkat pendidikan, pekerjaan, paritasdan jenis persalinan tidak memiliki perbedaan yang bermakna atau dalam kata lain karakteristik responden adalah sama (komparabel). Hal tersebut sesuai dengan pernyataan dari Sudigdo Sastroasmoro and Ismael ${ }^{15}$ bahwa agar kelompok eksperimental mendapatkan hasil yang sahih, maka karakteristik kelompok yang diperbandingkan harus seimbang (sama). Jadi, jika hasil akhir penelitian terdapat perbedaan efek antara kedua kelompok, maka perbedaan itu disebabkan oleh adanya perlakuan.

Tabel 2 Komparabilitas Pemberian Prelaktal Bayi BaruLahir

\begin{tabular}{|c|c|c|c|c|c|c|}
\hline \multirow{2}{*}{ No. } & \multirow{2}{*}{ Variabel } & \multicolumn{2}{|c|}{ Perlakuan } & \multicolumn{2}{|c|}{ Kontrol } & \multirow{2}{*}{$p$} \\
\hline & & $\mathrm{N}$ & $\%$ & $\mathrm{~N}$ & $\%$ & \\
\hline \multirow[t]{3}{*}{1.} & Umur Ibu & & & & & \\
\hline & a. 20-35 tahun & 28 & 84,85 & 30 & 88,24 & 0,48 \\
\hline & b. $<20,>35$ & 5 & 15,15 & 4 & 11,76 & \\
\hline \multirow[t]{3}{*}{2.} & Tingkat Pendidikan & & & & & \\
\hline & a. Pendidikan tinggi & 15 & 45,45 & 19 & 55,88 & 0,39 \\
\hline & b. Pendidikan rendah & 18 & 54,55 & 15 & 44,12 & \\
\hline \multirow[t]{3}{*}{3.} & Pekerjaan & & & & & \\
\hline & a. Bekerja & 3 & 9,09 & 5 & 14,71 & 0,37 \\
\hline & b. Tidak bekerja & 30 & 90,91 & 29 & 85,29 & \\
\hline \multirow[t]{3}{*}{4.} & Paritas & & & & & \\
\hline & a. Primipara & 16 & 48,48 & 18 & 52,94 & 0,71 \\
\hline & b. Multipara & 17 & 51,52 & 16 & 47,06 & \\
\hline \multirow[t]{3}{*}{5.} & Jenis Persalinan & & & & & \\
\hline & a. Normal & 25 & 75,76 & 21 & 61,76 & 0,21 \\
\hline & b. Tidak normal & 8 & 24,24 & 13 & 38,24 & \\
\hline
\end{tabular}


3. Pengaruh Konseling Laktasi pada Ibu Hamil Trimester III terhadap Pemberian Prelaktal Bayi Baru Lahir

Responden pada penelitian ini dibagi menjadi kelompok perlakuan dan kontrol. Kelompok perlakuan mendapatkan kelas ibu hamil dan konseling laktasi per individu, sedangkan kelompok kontrol mendapatkan kelas ibu hamil saja.

Tabel 3. Pengaruh Konseling Laktasi pada Ibu Hamil Trimester III terhadap Pemberian Prelaktal Bayi Baru Lahir

\begin{tabular}{lcccccc}
\hline Variabel & $\begin{array}{c}\text { Tidak } \\
\text { memberi }\end{array}$ & Memberi & $\begin{array}{c}\text { \% Tidak } \\
\text { Memberi }\end{array}$ & RR & Cl 95\% & p \\
\hline Kelompok & & & & & & \\
Perlakuan & 23 & 10 & 60,70 & 1,69 & $(1,06-2,68)$ & 0,01 \\
Kontrol & 14 & 20 & 30,30 & 1 & & \\
\hline
\end{tabular}

Tabel 3 menunjukkan bahwa proporsi ibu tidak memberikan prelaktal pada kelompok intervensi lebih tinggi dibandingkan dengan kelopmpok kontrol; $69 \%$ vs $30 \%, p=0,01$ dengan $\mathrm{RR}=1,69(95 \% \mathrm{Cl}: 1,06-2,68)$ sehingga terdapat perbedaan yang bermakna secara statistik pada kelompok perlakuan dengan kelompok kontrol. Analisis ini menunjukkan bahwa $\mathrm{HO}$ ditolak yang berarti proporsi ibu yang mendapatkan konseling laktasi pada kehamilan trimester ketiga 1,69 kali berpeluang lebih besar tidak memberikan prelaktal daripada ibu yang tidak mendapatkan konseling laktasi. Pada kelompok perlakuan, ibu yang memberikan prelaktal sebesar 10 orang $(29,41 \%)$. Pada kelompok kontrol, ibu yang memberikan prelaktal sebesar 20 ibu $(70,58 \%)$.

Pada penelitian ini didapatkan proporsi ibu yang mendapatkan konseling laktasi pada kehamilan trimester ketiga 1,69 kali berpeluang lebih besar tidak memberikan prelaktal daripada ibu yang tidak mendapatkan konseling laktasi. Terdapat perbedaan kelompok perlakuan dan kontrol karena pada kelompok perlakuan diberikan kelas ibu hamil dan konseling laktasi per individu sedangkan pada kelompok kontrol hanya mendapatkan kelas ibu hamil saja.

Kedua kelompok telah menghadiri kelas ibu hamil yang diselenggarakan rutin satu bulan sekali oleh tenaga kesehatan di wilayah kerja Puskesmas Sokaraja I Kabupaten Banyumas. Direktorat Jenderal Bina Gizi and Kesehatan Ibu Anak Kementerian Kesehatan Republik Indonesia ${ }^{16}$ membuat program kelas ibu hamil di Indonesia untuk meningkatkan derajat kesehatan ibu dan anak terutama pada kelompok yang rentan kesehatan yaitu ibu hamil, bersalin, dan bayi pada masa perinatal.

Kelas ibu hamil merupakan sarana untuk belajar bersama tentang kesehatan ibu hamil dalam bentuk tatap muka yang berkelompok. Kelas ibu hamil difasilitasi oleh tenaga kesehatan dengan menggunakan paket berupa buku KIA, flip chart (lembar balik), pedoman pelaksanaan kelas ibu hamil, pegangan fasilitator kelas ibu hamil dan buku/CD senam hamil. Semua responden penelitian mengikuti kelas ibu hamil. Peneliti menghadiri dan mengobservasi pelaksanaan kelas ibu hamil yang diselenggarakan tenaga kesehatan tersebut. Materi tentang ASI Eksklusif sudah disampaikan sesuai dengan materi pegangan fasilitator standar Direktorat Jenderal Bina Gizi \& Kesehatan Ibu Anak Kementerian Kesehatan Republik Indonesia.

Setelah semua responden penelitian mengikuti kelas ibu hamil, pada kelompok perlakuan ditambahkan konseling laktasi, sedangkan pada 
kelompok kontrol tidak mendapatkan konseling laktasi.

Konseling adalah cara bekerja sama dengan orang, dimana kita berusaha memahami perasaan mereka serta membantu mereka memutuskan apa yang dilakukan. ${ }^{17}$ Konseling dapat merubah perilaku klien, memecahkan masalah klien, menjadikan mental klien lebih positif serta dapat mengambil keputusan sendiri yang telah dibantu oleh konselor. Hal tersebut sesuai dengan pernyataan Pender et al dalamTomey ${ }^{18}$, yang menyatakan bahwa promosi kesehatan atau pemanfaatan diri akan menambah kemampuan untuk melakukan tindakan dan perbuatan dari suatu perilaku. Pengaruh positif pada suatu perilaku akibat pemanfaatan diri yang baik dapat menambah hasil yang positif. Konseling merupakan salah satu promosi kesehatan yang dapat membantu klien dalam memecahkan permasalahannya, sehingga klien dapat mengambil keputusan yang lebih positif.

World Health Organization/UNICEF ${ }^{17}$ menyatakan bahwa konseling laktasi akan berjalan efektif jika konselor melalui tahap mendengar dan mempelajari terlebih dahulu supaya dapat memberikan bantuan dan informasi yang sesuai dengan kebutuhan klien. Tahap mendengar dan mempelajari tersebut meliputi: menggunakan komunikasi non-verbal, mengajukan pertanyaan terbuka, menggunakan respon dan gerakan tubuh yang menunjukkan perhatian, mengatakan kembali yang ibu katakan, berempati dan menghindari kata-kata yang menghakimi.

Konseling laktasi yang dilakukan oleh konselor laktasi secara per individu tersebut dapat membantu permasalahan atau ketidakpahaman tentang hal menyusui. Konseling secara individu itu dapat membantu ibu dalam mengkonsultasikan permasalahan yang dihadapi atau ketidakpahaman tentang masalah menyusui dengan lebih percaya diri dan terbuka kepada konselor. Maka dari itu, dengan adanya konseling, kelompok perlakuan lebih sadar dan memahami pentingnya pemberian ASI Eksklusif dan bahaya pemberian prelaktal dibandingkan dengan kelompok kontrol sehingga kelompok perlakuan lebih besar berpeluang untuk tidak memberikan prelaktal pada bayi baru lahir.

Hal tersebut sesuai dengan penelitian sebelumnya oleh Romawati ${ }^{19}$ yang menyatakan bahwa ibu hamil trimester ketiga yang mendapatkan konseling ASI eksklusif secara intensif 23,92 lebih besar kemungkinan untuk menyusui dini dan memberikan kolostrum pada tiga hari pertama kelahiran dibandingkan ibu hamil trimester ketiga yang mendapatkan konseling ASI eksklusif tidak intensif. Penelitian tersebut juga diperkuat oleh Ambarwati ${ }^{20}$, yang menyatakan bahwa kelompok yang mendapatkan konseling laktasi secara intensif menunjukkan adanya perubahan skor pada semua anak dan peningkatan jumlah ibu yang memberikan ASI Eksklusif sampai 3 bulan pada anak yang dilahirkan selama penelitian menjadi 5 kali lipat dibandingkan dengan kelompok kontrol yang tidak mendapatkan konseling laktasi secara intensif. Penelitian yang berkaitan yang menyatakan bahwa konseling laktasi pada ibu dengan bayi BBLSR dapat meningkatkan inisiasi menyusui dini (IMD) dan proses menyusui tanpa ibu bertambah stres atau cemas.

Jenis prelaktal yang diberikan bayi baru lahir di wilayah kerja Puskesmas Sokaraja I diketahui ada dua yaitu susu formula dan madu. Jenis prelaktal pada kelompok perlakuan yaitu 7 (70\%) susu formula dan 3 (30\%) madu, serta pada kelompok kontrol yaitu susu formula 15 (75\%) dan madu 5 (25\%).

Hasil tersebut sesuai dengan penelitian Nguyen et al. ${ }^{12}$ yang menyatakan bahwa pada tiga hari pertama setelah kelahiran, bayi baru lahir 
sebesar 73,3\% diberikan prelaktal. Prelaktal yang diberikan susu formula sebesar 53,3\% dan air putih sebesar $44,1 \%$. Begitu pula penelitian oleh Riskesdas $^{5}$ yang menyatakan bahwa beberapa bayi baru lahir di Indonesia masih ada yang diberikan prelaktal. Jenisnya yaitu susu formula sebesar $70,3 \%$, madu sebesar $15,8 \%$, air putih sebesar $10,6 \%$ dan jenis prelaktal lainnya seperti air kopi, santan, biskuit, kelapa muda, air daun pare dan kurma sebesar 3,3\%.

\section{KESIMPULAN DAN SARAN}

Proporsi ibu yang mendapatkan konseling laktasi pada kehamilan trimester ketiga 1,69 kali berpeluang lebih besar tidak memberikan prelaktal daripada ibu yang tidak mendapatkan konseling laktasi.

\section{DAFTAR PUSTAKA}

1. BAPPENAS. Laporan pencapaian tujuan pembangunan milenium di Indonesia, 2011. Kementerian Perencanaan Pembangunan Nasional/Badan Perencanaan Pembangunan Nasional (BAPPENAS).

2. Dinas Kesehatan Jateng. Buku profil kesehatan Provinsi Jawa Tengah tahun 2012. Semarang.

3. Dinas Kesehatan Banyumas. 2012. Profil Kesehatan Kabupaten Banyumas tahun 2012. Banyumas: Dinas Kesehatan Kabupaten Banyumas.

4. World Health Organization. Infant and young child feeding. http://wwwwhoint/mediacentre/factsheets/ fs342/en/ (diakses tanggal 18 Maret 2014).

5. Riskesdas. 2013. Riset Kesehatan Dasar (RISKESDAS 2010). RI K, editor. Jakarta: Bhakti Husada

6. Riskesdas. R 2013. Riset Kesehatan Dasar (RISKESDAS 2013). RI BPdPKKK, editor. Jakarta: Bhakti Husada;

7. Rachmad E. Menkes minta Sumut fokus tingkatkan ASI Eksklusif dan penurunan kasus AIDS. http://beritasore. com/2013/04/29/menkes-minta-sumut-fokustingkatkan-asi-eksklusif-dan-penurunan-kasus-aids/; 2013 [diakses tanggal 28 Maret 2014, pukul 06.00 WIB].
8. Hikmawati I. Faktor-faktor risiko kegagalan pemberian ASI selama dua bulan. Semarang: Universitas Diponegoro; 2008.

9. Sholichah F. Studi kualitatif penyebab pemberian ASI Non Eksklusif pada ibu rumah tangga di Desa Ngemplak Kecamatan Undaan Kabupaten Kudus. Semarang: Universitas Negeri Semarang; 2011.

10. Prabantini D. A to Z makanan pendamping ASI. Yogyakarta: ANDI; 2010.

11. Rosha BC, Utami NH. Determinan pemberian makanan prelaktal pada bayi baru lahir di Kelurahan Kebon Kelapa dan Ciwaringin Kota Bogor. Penelitian Gizi dan Makanan. 2013;36:54-61.

12. Nguyen PH, Keithly SC, Nguyen NT, Nguyen TT, Tran LM, Hajeebhoy N. Prelacteal feeding practices in Vietnam: challenges and associated factors. BMC Public Health. 2013:1-11.

13. Nirmalasari D. Hubungan beberapa faktor ibu dengan pemberian makanan pralaktal pada bayi usia 0-1 bulan. Semarang: Universitas Diponegoro; 2008.

14. Moore ER, Coty M-B. Prenatal and postpartum focus groups With primiparas: breastfeeding attitudes, Support, Barriers, selfefficacy, and intention. Journal of Pediatric Health Care. 2006;20:35-46.

15. Sudigdo, Ismael S. Dasar-dasar metodologi penelitian klinis. keempat ed. Jakarta: Sagung Seto; 2012.

16. Direktorat Jenderal Bina Gizi, Kesehatan Ibu Anak Kementerian Kesehatan Republik Indonesia. Pedoman pelaksanaan kelas ibu hamil. Jakarta: Kementerian Kesehatan Republik Indonesia; 2011.

17. World Health Organization/UNICEF. Pelatihan konseling menyusui modul 40 jam WHO/UNICEF: WHO/UNICEF; 2011.

18. Tomey A, M \& Alligood,. Nursing theorists and their work, 6th edition. St. Louis, Missouri: C.V. Mosby Company; 2006.

19. Rohmawati R. Pengaruh konseling ASI Eksklusif pada ibu hamil trimester ketiga terhadap penyusuan dini dan pemberian kolostrum. Jogjakarta: Universitas Gadjah Mada; 2008.

20. Ambarwati R. Konseling Laktasi Intensif dan Pemberian Air Susu Ibu (ASI) Eksklusif Sampai 3 Bulan. Media Medika Indonesiana. 2012;46:201-8. 